\title{
NOTAS SOBRE A FORMAÇÃO DE UM SISTEMA TRANSNACIONAL DE ENSINO SUPERIOR
}

\author{
Carlos Benedito Martins*
}

\begin{abstract}
O presente artigo, tendo como referência analítica a relação reciproca entre processo de globalização e ensino superior, tem por objetivo abordar determinas transformações que estão ocorrendo no ensino superior nas sociedades contemporâneas. Apoiado numa bibliografia pertinente ao tema, o artigo salienta que, no contexto da globalização, o ensino superior não se confina mais nos limites das sociedades nacionais, mas transborda para além de suas fronteiras. Indica a emergência de determinados acontecimentos ocorridos nas últimas décadas que conduziram o ensino superior a atuar num espaço transnacional. As informações fornecidas pelo artigo tendem a indicar que, nas sociedades contemporâneas, o ensino superior vem adquirindo, cada vez mais, uma dimensão relacional, de tal modo que as universidades e seus respectivos países estão constantemente se comparando e competindo uns com os outros em busca de prestígio acadêmico no contexto internacional do ensino superior.
\end{abstract}

PALAVRAS-CHAvE: Desterritorialização do ensino superior. Mobilidade acadêmica internacional. Rankings internacionais. World class University

\section{INTRODUÇÃO}

O ensino superior contemporâneo, em nível internacional, encontra-se imerso num turbilhão de profundas transformações sociais, políticas, econômicas e culturais que atingem, de modo variável, a maioria dos países. O presente artigo assume o pressuposto de que uma adequada compreensão das mudanças que estão em curso no ensino superior contemporâneo necessita considerar tanto o funcionamento de seus diversos sistemas nacionais quanto o espaço transnacional desse nível de ensino, bem como as complexas relações existentes entre essas duas dimensões nas quais ocorre sua atuação. Este artigo assume também que o fenômeno da globalização - compreendido como um processo multidimensional - constitui uma das características centrais das sociedades contemporâneas. Ao manifestar uma complexa intensificação de interconexões transnacionais nos planos econômico,

* Universidade de Brasília (UnB), Instituto de Ciências Humanas, Departamento de Sociologia.

Campus Universitário UnB. Dept ${ }^{\circ}$ de Sociologia. Asa Norte. Cep: 70910-900. Brasília - Distrito Federal - Brasil. carlosb@unb.br político, cultural e acadêmico, o processo de globalização tornou-se uma potente força na produção de transformações em várias esferas da vida social contemporânea. Ao analisar o fenômeno da globalização, Turner e Khondker destacam que qualquer investigação sociológica, nos dias atuais, que pretenda abordar uma nação, uma região, uma remota cidade, e (ou) um fenômeno específico, tal como o ensino superior, corre o risco de se tornar incompleta, caso não contemple o contexto global e suas relações com os níveis local e nacional (Turner; Khondker, 2010).

No contexto da globalização, as atividades econômicas, políticas e culturais não se confinam nos limites das sociedades nacionais, mas tendem a transbordar para além de suas fronteiras. Essa mesma dinâmica do processo de globalização encontra-se presente também na estruturação do ensino superior contemporâneo. Nessa direção, é possível constatar a existência de sistemas nacionais de ensino nos diversos continentes e, simultaneamente, a constituição de uma esfera transnacional na qual se movimentam milhares de instituições, milhões de estudantes, e a presença de uma pluralidade de atores envol- 
vidos com o funcionamento e a dinâmica do ensino superior (Neves, 2011; Gibbs, 2010; Knight, 2008; Ferreira, 2006).

As análises sociológicas a propósito da inserção do ensino superior no processo de globalização encontram-se ainda numa etapa incipiente, quando comparadas com o expressivo volume de produção acadêmica existente a respeito das dimensões econômicas, políticas, tecnológicas e culturais que o integram (Held; McGrew, 2012; O’Byrne; Hensby, 2011; Lemert; Elliot, 2010). Ao mesmo tempo, verifica-se que uma parte significativa de trabalhos voltados à compreensão das relações entre globalização e ensino superior tem sido produzida fundamentalmente por pesquisadores provenientes da área de educação (Margison e col., 2011; Marige; Foskett, 2010; Knight, 2008; King, 2004; Scot, 1998). Os trabalhos realizados por educadores em diferentes partes do mundo têm oferecido um significativo aporte para a compreensão das relações entre globalização e ensino superior. No entanto, a sociologia, tanto internacional quanto a realizada na sociedade brasileira, tem o desafio de incluir em sua agenda de trabalho, de forma sistemática, a análise da inserção do ensino superior no contexto da globalização, preservando um diálogo com outras disciplinas das ciências humanas que vêm abordando a constituição de uma sociedade global.

Este artigo, tendo como ponto de referência analítica a relação reciproca entre processo de globalização e ensino superior, tem por objetivo abordar, brevemente, determinados fenômenos que têm contribuído para a cons+ tituição de um novo locus de funcionamento a do ensino superior nas sociedades contempoi râneas, vale dizer, de um espaço transnacional $\overrightarrow{~ d e ~ e n s i n o ~ s u p e r i o r . ~ A ~ e m e r g e ̂ n c i a ~ d e s s a ~ n o v a ~}$ esfera de atuação do ensino superior expressa o rompimento de determinados sistemas de ensino superior e de seus atores com os limites de suas fronteiras nacionais e um alargamento de sua atuação em direção a uma esfera transnacional.

\section{GLOBALIZAÇÃO E ENSINO SUPE- RIOR}

O processo de globalização que vem se formando nas últimas décadas se entrelaça com a manifestação de uma série de eventos que indicam a configuração de novos espaços pós-nacionais. Nessa direção, observa-se a existência de uma economia global que incorpora desigualmente nações no contexto de uma nova divisão internacional do trabalho, verifica-se a circulação de um intenso fluxo de capital financeiro que se desloca com velocidade de uma nação para outra em busca de maior lucratividade, e percebe-se a também proliferação de instituições supranacionais que têm impacto nas agendas sociais de numerosos países, etc. Os governos nacionais, longe de desaparecerem, passam a manter complexas relações com esses organismos multilaterais. Ao mesmo tempo, constata-se uma acentuada mobilidade de pessoas que se deslocam com inusitada frequência entre diferentes nações seja por decisão voluntária, seja por processo de migração -, o aparecimento de novas tecnologias de comunicação interligando indivíduos que habitam em diferentes lugares do planeta, a circulação internacional do conhecimento, a constituição de uma mídia mundial, o surgimento de cidades globais, o aparecimento de uma sociedade civil mundial, etc. (Turner e Elliot, 2012; Perkins e Thorns, 2012; Urry e Elliot, 2010; Knight, 2003; Delanty, 2002, 2009, Robertson, 2000).

$\mathrm{O}$ advento do processo de globalização implicou profundas transformações na natureza da universidade. A concepção de universidade formulada por Humboldt, que orientou por um longo período histórico sua estruturação em diversos países, gradativamente passou a ceder lugar a novos arranjos institucionais que vêm se difundindo globalmente (Kwiek, 2006, 2005; Gibbons, 2004, 1998; Readings, 1996). A clássica análise, realizada por Clark Kerr (2001), em seu livro The uses of the University, ressaltou que as complexas relações 
que algumas universidades passaram a estabelecer com as demandas econômicas, políticas e com amplos setores da sociedade contemporânea alteraram sua natureza institucional. Para Clark Kerr, o aparecimento da multiversidade constituiu um marco na inflexão do modelo de universidade concebida por Humboldt. Constata-se que, a partir das últimas décadas do século passado, delineou-se uma nova concepção, que atribui à universidade uma função estratégica no crescimento das economias nacionais e um papel no incremento da competitividade dos países no contexto da economia global. Diante das conexões que a universidade passou a manter com as demandas econômicas e com a formação de quadros profissionais especializados para atendê-las, Zygmunt Bauman assinalou que determinados princípios acadêmicos que orientaram a universidade por um longo período têm sido considerados obsoletos por vários agentes que circulam em seu interior (Bauman, 2012, 1997).

Ao analisar as relações entre ensino superior e processo de globalização, Castells destacou que, além da emergência de um mercado econômico global, que se intensificou nas últimas três décadas, vem ocorrendo a produção de um volume de conhecimentos científico e tecnológico que mantém relação com a acumulação do capitalismo global. Em sua perspectiva, em contraste com fatores produtivos tradicionais, tais como terra, recursos naturais, esforço humano e maquinarias, nas sociedades contemporâneas, a produção de novos conhecimentos transformou-se em um novo fator de produção. Nessa direção, Castells e outros autores têm ressaltado que, no contexto atual, a atividade de pesquisa não repousa mais, como no passado, apenas na autonomia intelectual do pesquisador individual. Tanto é assim que, em larga medida, em numerosos países, a produção de conhecimentos tem sido com frequência subsidiada por fundos governamentais ou privados, que estabelecem parcerias com equipes de pesquisadores de universidades e (ou) outras instituições congêneres, como um meio para incrementar a competitividade no mercado global. Nessa perspectiva, as universidades que realizam pesquisa capaz de gerar inovações nas esferas econômica e social passaram a ser consideradas como atores relevantes no processo de globalização e tendem a ocupar uma posição destacada nos contextos nacional e (ou) internacional do ensino superior (Castells, 1994; Robertson, 1998).

Uma das faces mais visíveis do processo de globalização no ensino superior manifesta-se por meio da participação de organismos multilaterais na formulação de sua agenda internacional realizada por instituições como UNESCO, Banco Mundial, OCDE, União Europeia etc. Com frequência, as propostas de novos modelos para o ensino superior são elaboradas por essas agências que circulam tanto nos espaços regionais, nacionais como num circuito mundial (Manicas, 2004; Enders, 2002; Wende, 2001). No entanto, as transformações que vêm ocorrendo em diferentes espaços universitários nacionais não constituem uma consequência direta das recomendações das organizações internacionais, tampouco representam um desdobramento de constrangimentos e imposições vindos do exterior. Como indica a bibliografia sobre essa temática, em determinadas reformas realizadas em diversos contextos societários, mesmo quando classificadas como "internacionais", as agendas dos organismos multilaterais tendem a ser (re)traduzidas e (re)apropriadas pelos atores nacionais. A análise do impacto dessas agências no ensino superior coloca em relevo a necessidade de se cotejarem as complexas relações que envolvem a interação entre as dimensões global e nacional, uma vez que as diferentes faces do processo de globalização encontram-se sujeitas às influências das sociedades nacionais (Douglas; King, 2009; Scott, 2006; Antunes, 2005; Guadilla, 2004; Currie, 2003)

$\mathrm{Na}$ análise de alguns autores, além das agendas dos organismos multilaterais que reverberam em diferentes países, configurou-se, pouco a pouco, a partir das últimas décadas do 
século passado, um novo modelo de estruturação das universidades denominado de Emerging Global Model (EGM), cuja fonte inicial de inspiração foi a estrutura acadêmica das universidades norte-americanas que, a partir da Segunda Guerra, assumiu uma posição dominante no contexto internacional do ensino superior (Clark, 2008; 1990).

Esse novo modelo de organização da vida acadêmica, que vem sendo adotado mundo afora, possui determinadas características comuns no modus operandi das universidades, entre as quais se destacam: (i) são instituições cuja vocação acadêmica transcende suas fronteiras nacionais, uma vez que se propõem a formar indivíduos capazes de atuar profissionalmente em distintos contextos da sociedade global; (ii) seu foco principal baseia-se na atividade de pesquisa como um mecanismo de desenvolvimento econômico e social da economia global (iii) possuem uma elevada complexidade organizacional interna; (iv) utilizam uma sólida infraestrutura para pesquisa que possibilita a geração de novas descobertas científicas e tecnológicas; (iv) recrutam docentes que passam a integrar equipes interdisciplinares e estabelecem estreitas relações acadêmicas com parceiros internacionais; (v) adotam uma diversificação de captação de 농 recursos que inclui cobrança de anuidades, . parcerias com corporações e governos, criação de empresas como spin-offs a partir das quais docentes passam a explorar novos produtos ou serviços de alta tecnologia; (viii) utilizam estratégias de recrutamento internacional de estudantes, professores e administradores uni‡i versitários; (viii) participam, por meio de seus docentes e alunos, das atividades de corporações transnacionais, organismos multilaterais e de uma pluralidade de agências (governamentais, não governamentais nacionais e internacionais); (ix) introduziram, em seu interior, procedimentos de gestão empresarial tanto na cultura administrativa da universidade quanto na sua organização acadêmica (Mohrman; Baker, 2008; Clark, 2003; Deem, 2001).

\section{DESTERRITORIALIZAÇÃO DO ENSI- NO SUPERIOR: instalação de campi de universidades estrangeiras em vários países}

Um fenômeno que se encontra relacionado com o processo de globalização diz respeito ao incremento dos sistemas de mobilidade que surgiram no mundo contemporâneo. Vários autores têm salientado a importância de explorar sociologicamente o impacto dos diferentes sistemas de mobilidade na conformação da vida cotidiana dos indivíduos. Para John Urry, sistemas de mobilidade referem-se ao desenvolvimento de distintas tecnologias que permitem o deslocamento físico e (ou) virtual dos indivíduos e uma maior comunicação entre eles. Nesse sentido, destaca as inovações nos diferentes meios de transporte, o vertiginoso aumento das viagens aéreas que interligam velozmente cidades, países e continentes, o incremento do turismo, a existência de uma rede mundial de computadores, que propiciou o acesso de milhões de indivíduos à internet e ao uso do Skype, o aparecimento de novos aparelhos, que permitem uma rápida comunicação entre indivíduos, como os laptops e os telefones celulares (iPods, Smartphones, BlackBerry etc.). Essas inovações tecnológicas propiciaram uma circulação mundial de pessoas e de informações, permitindo aos indivíduos que têm acesso a esses instrumentos deslocarem-se pelos quatro cantos do mundo sem sair de um determinado lugar físico (Harvey; Thorns, 2012; Urry; Elliot, 2010; Ling, 2008; Kaufmann, 2003).

O processo de globalização no ensino superior impulsionou o crescimento do mercado internacional de trabalho para docentes, cientistas e administradores universitários, que passaram a utilizar o inglês como língua franca na comunicação acadêmica (Rostand, 2011). No entanto, um dos fenômenos mais salientes nesse processo diz respeito à crescente oferta de serviços educacionais por universidades estrangeiras que cruzam suas frontei- 
ras nacionais, instalando-se em outros países. Uma constelação de fatores tem contribuído para a produção desse fenômeno, entre os quais se observa a existência de uma demanda reprimida de acesso ao ensino superior em determinados países, uma revolução nas tecnologias de informação e a desregulamentação das trocas comerciais em geral. Muitas dessas instituições satélites estão localizadas em países nos quais os governos nacionais promoveram cortes orçamentários em seus sistemas de ensino superior e encorajaram o estabelecimento de joint ventures com universidades estrangeiras (Altbach; Knight, 2006).

Apesar da forte expansão do ensino que ocorreu a partir de meados do século passado no plano internacional, a demanda por ensino superior continua crescendo, mesmo em sociedades que estão abaixo de $20 \%$ na absorção de estudantes entre 18 e 24 anos de idade, tal como ocorre com Índia, China e muitos países da África. As regiões que mais importam serviços educacionais estão concentradas na Ásia, no Oriente Médio e na América Latina. Os maiores provedores são países de língua inglesa (Estados Unidos, Austrália, Nova Zelândia, Inglaterra). A partir de 2000, vários campi foram criados, especialmente no Oriente Médio e no Sudeste Asiático, de tal forma que, em 2009, existiam 162 campi internacionais (Wildavsky, 2010).

A Organização Mundial do Comércio (OMC), por meio do Acordo sobre o Comércio de Serviços (Gats), incluiu, em sua pauta de trabalho, a discussão de um marco regulatório para introduzir a educação no sistema multilateral de serviços. Nessa direção, pretende facilitar a desterritorialização do ensino superior por meio da educação à distância, do estabelecimento de franchising por parte de instituições de ensino, da utilização de joint ventures e também por meio da prática de branch campuses. Um acontecimento de significativa importância para o ensino superior foi a finalização da Rodada Uruguai de negociações comerciais em 1995, que, ao criar o Gats, lan- çou as bases que possibilitam às universidades estrangeiras estabelecerem campi em outros países, removendo obstáculos legais à realização dessas atividades. A educação constitui um dos doze serviços abrangidos pelo acordo, e o seu objetivo é promover a liberalização do comércio de serviços educacionais por meio da eliminação progressiva de barreiras comerciais. EUA, Nova Zelândia e Austrália são os países mais entusiastas dos benefícios do Gats, uma vez que são os maiores exportadores de serviços universitários (Altbach; Knight, 2006; Knight, 2003).

A instalação do campus da New York University (NYU) na cidade de Abu Dhabi, capital dos Emirados Árabes Unidos, representa um caso arquetípico no processo de satelitização de instituições estrangeiras em outros países. A NYU oferece, nessa cidade, cursos de graduação em artes e ciências. Além de absorver estudantes locais e de outras regiões do Oriente Médio e da Índia (Mumbai fica distante apenas duas horas e meia de voo), a NYU Abu Dhabi objetiva incorporar, no corpo discente, alunos provenientes dos Estados Unidos que desejem manter contato com outras culturas. Os dirigentes americanos da instituição procuram inserir seus estudantes num circuito acadêmico que eles denominam de global network university, no qual os alunos podem realizar parte do curso na sede central da instituição, na cidade de Nova York, bem como em outros campi que a NYU pretende instalar em Berlim, Florença e Shanghai. Com esse procedimento, seus dirigentes almejam formar cidadãos globais que, uma vez titulados, sejam capazes de atuar em qualquer parte do mundo (Wildavsky, 2010).

Para dirigir a instituição, foi recrutado o ex -presidente do Swarthmore College, que tem procurado absorver docentes do próprio quadro da NYU e também professores altamente qualificados de outras regiões do mundo. Para atrair esses professores, a instituição tem oferecido salários competitivos e benefícios como residência subsidiada, escolas gratuitas para seus filhos e bilhete aéreo anual em 
classe executiva para o país de origem. Os custos da instalação do campus foram inteiramente financiados pelos governantes dos Emirados Árabes Unidos, que também assumiram o pagamento do salário dos professores.

\section{MOBILIDADE ACADÊMICA TRANS- NACIONAL}

A mobilidade acadêmica possui uma longa tradição na história do ensino superior, uma vez que, novecentos anos atrás, estudantes de diversas origens europeias dirigiam-se às universidades de Bolonha, Paris e Oxford, construídas no período feudal. No entanto, nas últimas décadas, a mobilidade estudantil tornou-se um componente central na estruturação do ensino superior internacional. Em 1950, existiam 110 mil estudantes que cruzaram as fronteiras de seus países e estudavam em universidades estrangeiras. Nos primeiros anos da década de 1970, atingiu-se a cifra de 500 mil estudantes estrangeiros. A partir dos 1990, houve uma rápida expansão dessa circulação e, no final daquela década, registravam-se 1,75 milhão de estudantes. Em 2008, atingiu-se o patamar de 3,3 milhões de estudantes em cursos de graduação e pós-gradu$\stackrel{2}{5}$ a ação em instituições estrangeiras. Estima-se จे que, nos próximos dez anos, 7,5 milhões de estudantes estarão realizando seus estudos em universidades estrangeiras (Brooks e Waters, 2013; Banks, 2007). O rápido crescimento da mobilidade estudantil nas últimas décadas S tem impulsionado a formação de um espaço ₹ mundial de ensino superior, no qual se ins\& taurou uma acirrada competição entre deter今 minados países e instituições para absorvê-los, $\vec{i}$ visando a aumentar a internacionalização de seus sistemas nacionais de ensino superior e incrementar a competitividade econômica de suas sociedades no contexto da globalização (Woodfield, 2010).

De certa forma, a reputação de que as universidades norte-americanas passaram a usufruir mundialmente, após a Segunda Guerra, alimentou esse processo. Foi no período pós-guerra que determinadas universidades de pesquisa norte-americanas captaram vultosos fundos públicos e privados, estruturaram sólidos departamentos e laboratórios de investigação e obtiveram um número expressivo de Prêmios Nobel. Dessa forma, passaram a atrair estudantes estrangeiros de várias partes do mundo para realizar seus estudos de graduação e (ou) pós-graduação em suas universidades (Geiger, 2004). Ao mesmo tempo, os avanços tecnológicos nos meios de comunicação e de transporte, bem como determinadas orientações culturais que se encontram presentes em numerosas sociedades - que tendem a impelir os indivíduos a se moverem de suas localidades para outros países, que valorizaram a aprendizagem de novas competências linguísticas - possuem um significativo impacto na motivação dos indivíduos de realizarem seus estudos em universidades estrangeiras.

Os estudantes estrangeiros estão concentrados em países como EUA, Inglaterra, Alemanha, França, Austrália, Japão e Canadá, que absorvem $62 \%$ deles. Alguns países, como Austrália, Canadá, Inglaterra e Estados Unidos, recrutam estudantes como forma de captar recursos para suas universidades e para suas respectivas economias nacionais, uma vez que estabelecem a cobrança de elevadas taxas. A Nova Zelândia gera mais dividendos financeiros com o ensino superior do que com sua indústria de vinhos. O Canadá obtém maiores ganhos econômicos com o ensino superior do que com a exploração de madeira e carvão; o mesmo ocorre com a Inglaterra, onde o ensino superior suplantou, em volume financeiro, sua indústria automotiva (Wit, 2010). Estima-se que, nos Estados Unidos, os estudantes estrangeiros, no início dos anos 2000, aportaram 12 bilhões de dólares em sua economia e que essa cifra atinja o patamar de 18 bilhões de dólares na década de 2010 (OCDE, 2004).

Os Estados Unidos absorvem atualmente aproximadamente $22 \%$ dos estudantes que rea- 
lizam estudos no exterior. Dos 584 mil estudantes estrangeiros que frequentam as universidades americanas, metade procede de países asiáticos, com destaque para Índia (13\%), China (11\%), Coreia do Sul (9\%), Japão (7\%), Taiwan (5\%), Tailândia (1,5\%), Indonésia (1,3\%) e Malásia (1,2\%) (Altbach, 2004).

Quando se examinam os dados relativos à Inglaterra, observa-se que a China ocupa a primeira posição, uma vez que $15 \%$ dos estudantes estrangeiros nas universidades inglesas são procedentes daquele país. A seguir, aparecem Índia (7\%), Grécia (6\%), Irlanda (76\%), EUA (4,5\%) e Malásia (3\%). A Alemanha, que absorvia 259 mil estudantes em 2006, tem atraído um número significativo de estudantes da China (10\%), aparecendo, em seguida, Turquia (8\%), Polônia (6\%), Bulgária (7\%), Itália (3\%), França (2,5\%) e Grécia (2\%). A Alemanha tem utilizado a estrutura do DAAD - uma organização intermediária entre o ensino superior alemão e agências governamentais - como um mecanismo para promover a internacionalização de suas universidades (Green; Koch, 2010; Verbick; Lasanowski, 2007).

A França tende a atrair e a recrutar estudantes a partir de laços históricos e culturais que estabeleceu com determinados países. Nesse sentido, o Marrocos ocupa a primeira posição, representando $10 \%$ dos estudantes estrangeiros na França, seguido pela Argélia (9\%). No entanto, chama a atenção o crescimento de estudantes chineses em seu território. Em 1999, havia 1.300 estudantes chineses na França; em 2006, esse número saltou para 16 mil. O aumento é tão significativo, que a China ocupa atualmente a terceira posição, com 6\% de estudantes. Embora a França venha introduzindo a língua inglesa em algumas de suas instituições, observa-se, com exceção da China, uma inexpressiva presença de estudantes de países asiáticos em seu território, como Malásia, Hong Kong, Singapura, países que, com frequência, exportam estudantes.

A Austrália vem desenvolvendo uma política sistemática de recrutamento de es- tudantes internacionais. Em 2001, havia, em suas universidades, 105 mil estudantes estrangeiros. Esse número aumentou para 207 mil em 2006. A Austrália construiu uma sólida rede de recrutamento de estudantes internacionais em vários países através de uma organização privada denominada IDP. Os dados indicam que ela tem recrutado principalmente estudantes na Ásia. A China representa o maior contingente de estudantes estrangeiros na Austrália (30\%). A seguir, aparecem Índia (17\%), Malásia (9\%), Hong Kong (8\%), Indonésia (6\%) e Coreia do Sul (5,7\%) (Banks, 2007).

Alguns trabalhos têm destacado o recrutamento de estudantes estrangeiros que vem sendo realizado por países que tradicionalmente se comportavam como exportadores de corpo discente. Nesse sentido, assinalam a emergência de novos competidores no mercado mundial de ensino superior. A Jordânia planeja recrutar 100 mil estudantes até o ano de 2020; Singapura aspira absorver $150 \mathrm{mil}$ até 2015; o Japão almeja arregimentar 300 mil estudantes estrangeiros até 2020. A China planeja incorporar 500 mil estudantes de várias nacionalidades em suas universidades até o ano de 2020. Para atingir suas metas, esses países têm realizado reformas institucionais, introduzindo a língua inglesa em seus cursos, construindo uma infraestrutura física capaz de acomodar milhares de novos estudantes e criando fundos de bolsas de estudos capazes de atrair um número expressivo de estudantes estrangeiros (Bhandari; Blumenthal, 2011; Gürüz, 2008).

Não são apenas os alunos talentosos que determinadas universidades estrangeiras procuram atrair. Várias instituições vêm admitindo professores estrangeiros que possuam uma sólida formação acadêmica e que sejam capazes de integrar suas equipes de pesquisa. Sites especializados e revistas como Times Higher Education publicam com frequência, em suas páginas, oferta de empregos para professores e pesquisadores em universidades situadas em diferentes países. Simultaneamente, várias 
instituições que almejam ocupar posição de destaque no mercado global de ensino superior e (ou) branch campuses vêm contratando também ex-reitores e (ou) administradores de universidades que gozam de prestígio internacional. Nesse sentido, esta ocorrendo a formação de um novo mercado de trabalho para quadros universitários, situado além das fronteiras dos sistemas nacionais de ensino superior.

\section{EMERGÊNCIA DOS RANKINGS IN- TERNACIONAIS}

Num período mais recente, ocorreu a emergência de rankings globais, que visam a classificar as instituições de ensino superior num plano internacional. Seu surgimento possui conexões com um conjunto de mudanças que estão em curso no ensino superior, tais como: expansão e diversificação dos sistemas nacionais, incremento da mobilidade estudantil, competição entre instituições para recrutamento internacional de estudantes talentosos e docentes de prestígio, intensificação da corrida, em várias partes do mundo, pelo estabelecimento de world-class universities etc. $\mathrm{Na}$ medida em que o ensino superior se tornou um ator estratégico na produção de novos coเి nhecimentos e um componente relevante no : processo de competitividade, seu desempenho também passou a ser comparado numa escala internacional. O surgimento dos rankings globais expressa uma metáfora do processo de globalização do ensino superior e constitui um จ dos produtos da formação de um sistema trans+ nacional de ensino superior. Ao mesmo tempo, a representa um dos elementos que estimulam o

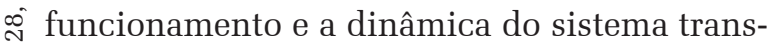
nacional de ensino superior (Hazelkorn, 2011, 2008; Altbach, 2001).

O ranking que ocupou uma posição de destaque na cena internacional e teve uma forte repercussão na dinâmica do mercado global de ensino superior foi o Academic Ranking of World Universities, elaborado pela Shanghai
Jiao Tong University em seu Instituto de Ensino Superior. A primeira edição desse ranking surgiu em 2003, mas sua formulação vinha sendo elaborada desde 1999. O impulso para sua elaboração foi dado pelos administradores da universidade, preocupados com o declínio acadêmico das universidades chinesas. Em função dessa inquietação, foi realizada uma série de discussões internas, a fim de criar uma metodologia para medir a distância entre as universidades chinesas e as de maior reputação mundial. Um professor de química dessa universidade, Nian Cai Liu, que exercia o cargo de diretor do Instituto de Ensino Superior, teve papel destacado na elaboração desse ranking. Quando Nian Cai Liu expandiu seu universo de comparação, incluindo, em sua análise, 2 mil instituições de ensino superior estrangeiras, para classificar as 500 mais destacadas, sua iniciativa adquiriu uma expressiva visibilidade diante dos governos nacionais, entre reitores, administradores universitários, professores, alunos, fundações de pesquisa, etc. Um dos seus efeitos mais visíveis foi o de incentivar a corrida pela competição de prestigio acadêmico no mercado global de ensino superior (Liu, 2009).

O critério adotado pelo Academic Ranking of World Universities (ARW) privilegia a produtividade em pesquisa, incluindo número de artigos publicados nas revistas Science e Nature, citações de artigos de pesquisadores mensurados por Thomas Scientific, e por Science and Social Science Citations, professores que ganharam Prêmio Nobel, alunos distinguidos com Prêmio Nobel e (ou) Fiels Medals etc. Os critérios adotados pela Shangai Jiao Tong University tendem a favorecer as antigas e prestigiosas universidades ocidentais, principalmente aquelas que têm produzido ou atraído ganhadores de Prêmio Nobel. Em geral, são universidades que remuneram seus docentes e administradores com elevados salários e que também possuem laboratórios, infraestrutura física e bibliotecas de excepcional qualidade. Os indicadores usados valorizam as publica- 
ções em língua inglesa e determinadas revistas científicas internacionalmente referenciadas, algumas das quais se encontram abrigadas no interior das universidades que ocupam posições destacadas nos rankings globais.

Atualmente, existem mais de uma dezena de rankings globais. Ao lado do criado pela Universidade de Shanghai destaca-se o World University Ranking (WUR), uma iniciativa da The Times Higher Education que apresenta uma lista hierarquizada de 200 universidades, classificadas em duas grandes categorias, por continentes e por cinco áreas de saber. WUR vem desenvolvendo um ambicioso esforço para apreender com os resultados dos primeiros rankings globais e proporcionar uma perspectiva multifacetada do ensino superior num plano internacional. Nesse sentido, tem procurado incluir várias funções da atividade universitária, tais como a pesquisa, o ensino, as relações com a empresa e o nível de internacionalização das instituições, vale dizer, sua capacidade de atrair estudantes e professores estrangeiros. Inclui também análise de citações de trabalhos produzidos no interior das instituições e leva em consideração as opinióes de acadêmicos e de profissionais sobre a reputação das instituições a serem avaliadas (Altbach, 2001).

Atualmente, os rankings globais orientam a conduta de uma pluralidade de atores, como governos nacionais que desenvolvem esforços para impulsionar suas melhores universidades por meio de seus policy makers, reitores que procuram criar estratégias para tornar suas instituições competitivas internacionalmente, empregadores que avaliam a origem dos títulos universitários dos que demandam um posto de trabalho, alunos que desejam realizar formação pós-graduada em instituições estrangeiras. A cultura dos rankings globais tende a ser internalizada na conduta dos administradores e no corpo docente das instituições que desfrutam e (ou) almejam uma posição de destaque no seu interior. Os rankings globais converteram-se num poderoso instrumento acadêmico que orienta as ações e percepções de uma multiplicidade de atores e tem incitado uma constante vigilância institucional na performance das universidades que pleiteiam participar da disputa pelas posições mais prestigiosas no cenário internacional do ensino superior (Sauder; Espeland, 2009).

\section{A CORRIDA PARA CONSTRUÇÃO DE WORLD CLASS UNIVERSITIES}

O processo de formação de um sistema transnacional de ensino superior não se restringe à instalação de campi de universidades estrangeiras em outros países, à crescente circulação internacional de estudantes e professores e à emergência dos sistemas de rankings internacionais. Outra dimensão desse processo manifesta-se por meio do empenho de vários países em criar e (ou) transformar determinadas instituições de ensino superior em world class university. Em numerosas sociedades nacionais, governantes, policy makers, reitores, entres outros atores, consideram que a construção de universidades que desenvolvem pesquisas de ponta poderá reter universitários em seus respectivos territórios, bem como atrair um número considerável de estudantes e professores estrangeiros, ampliando o processo de internacionalização de suas instituições (Deem; Mok, 2008).

A noção de world class university surgiu recentemente na discussão do ensino superior internacional. Tudo leva a crer que esse conceito foi produzido, concomitantemente, no interior de determinados organismos internacionais, como o Banco Mundial, e por acadêmicos que concentram seus trabalhos na temática do ensino superior (Liu; Wang; Cheng, 2011; Salmi, 2009; Mohrman; Baker, 2008; Altbach, 2003). Essa noção procura expressar certas características apresentadas por determinadas universidades, tais como presença de uma cultura acadêmica consolidada, existência de normas institucionais compartilhadas 
pelos seus membros, padrão de excelência em pesquisa e ensino, absorção de um quadro docente de alto nível acadêmico, rigorosa seleção intelectual dos alunos. Ao mesmo tempo, adotam um expressivo recrutamento internacional de seus docentes e estudantes, de tal modo que criam um ambiente cosmopolita nas discussões acadêmicas que ocorrem em seu interior. Contam também com uma adequada estrutura financeira capaz de custear adequadamente seus laboratórios, bibliotecas, de fornecer bolsas de estudos para estudantes nacionais e estrangeiros e oferecer salários competitivos no processo de recrutamento de seus docentes. As universidades que possuem essas características tendem a desfrutar de um elevado grau de reconhecimento acadêmico no espaço internacional e, em geral, ocupam posições privilegiadas nos rankings internacionais de ensino superior (Salmi, 2009; Altbach, 2003). De certa forma, essas instituições aproximam-se do modelo de universidade delineado no Emerging Global Model, que, conforme foi assinalado anteriormente, inspirou-se na estrutura acadêmica das universidades norte-americanas que, a partir da Segunda Guerra, assumiram uma posição dominante no contexto internacional do ensino superior (Roger, 2004; Clark, 1990). A concepção de world class university, paulati-

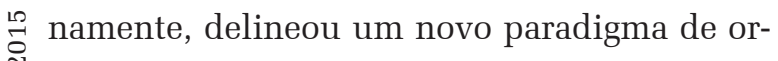
: ganização do ensino superior, que passou a ser discutido em vários países.

A seguir, o artigo, destacará, de maneira breve, o impacto do modelo de organização da vida universitária preconizado pela concepção de world class university, em determinados pa₹ íses da Ásia, Oriente Médio e Europa.

O sistema de ensino superior na China, tal como tem ocorrido com outros países asiáticos, mostrou-se receptivo a esse novo paradigma de organização do ensino superior. A China tem experimentado um rápido desenvolvimento do ensino superior desde 1980, contando, atualmente, com aproximadamente 1.700 instituições bastante diversificadas. Em 2009, o sistema de educação terciária absorvia aproximadamente 29 milhões de estudantes, tornando-se o maior do mundo em termos quantitativos (Wang, 2010). A China manifesta, atualmente, um dos mais ambiciosos planos para estabelecer um grupo seletivo de universidades, com vistas a ocupar uma posição de destaque em seu sistema de ensino superior e de proeminência acadêmica no plano internacional. Em 1993, o então presidente Jiang Zemin anunciou a criação do Projeto 211, que foi implantado nos anos seguintes com uma provisão de fundos da ordem de 20 bilhões de dólares destinados a uma centena de universidades chinesas. A iniciativa objetivava a construção de novas estruturas físicas e a edificação de laboratórios de pesquisa para desenvolver a capacidade em determinadas disciplinas, tais como saúde, medicina e tecnologia. Posteriormente, no ano de 1998, o mesmo presidente anunciou o Projeto 985, cujo alvo era impulsionar dez universidades que foram consideradas as mais importantes academicamente no país, entre as quais Beijing, Tsinghua, Zhejan, Nanjing, Shanghai, Jiao Tong etc. e que dispunham de um potencial para competir internacionalmente em termos de prestígio acadêmico (Guo, 2008).

A disposição de incluir algumas de suas instituições entre as mais bem posicionadas nos rankings internacionais repercutiu na vida acadêmica; os professores universitários chineses encontram-se sob forte pressão para aumentar o volume de suas publicações em periódicos indexados e de impacto em suas respectivas áreas, sob pena de perder seus postos de trabalho. Determinadas instituições chinesas, ao vincularem a permanência do docente à sua produção científica, eliminaram a estabilidade no emprego e suprimiram a figura do full professor. Essas medidas, que visavam ao aumento do rendimento acadêmico, transformaram a China num dos maiores produtores de artigos científicos no mundo acadêmico, atingindo o patamar de $6 \%$ do volume mundial. Nessa esteira, ocorreu, recentemente, uma significativa expansão do seu sistema de pós-graduação. 
Ao mesmo tempo, a China tornou-se uma das maiores destinações de estudantes asiáticos e também de outras regióes do mundo, ao lado dos Estados Unidos, Inglaterra, França, Alemanha e Austrália. Entre 1997 e 2007, o número de estudantes internacionais em seu sistema saltou de 39 mil para 195 mil. Parte desse recrutamento de estudantes internacionais devese também ao fato de determinadas áreas de conhecimento, tais como medicina e administração, passarem a adotar a língua inglesa em seus programas de ensino (Hvistendahl, 2008).

No entanto, um dos maiores desafios para a China transformar-se num polo competitivo no sistema mundial de ensino superior repousa na ausência de liberdade de expressão no interior das instituições acadêmicas. Se, por um lado, o governo central permite críticas com relação à política econômica, as autoridades nacionais exercem um rígido controle nas atividades acadêmicas de professores visitantes e monitoram, de perto, as intervenções de docentes e estudantes locais. Nesse sentido, por mais que se crie uma adequada infraestrutura acadêmica e uma política de atração de estudantes e professores estrangeiros, falta às instituições chinesas a atmosfera propiciada pela liberdade de expressão, que constitui um elemento fundamental nas universidades que ocupam o topo das posições nos rankings internacionais (Wildavsky, 2010).

A Índia também vem procurando realizar determinadas reformas em seu sistema de ensino superior na esteira do modelo de world class university. Absorvendo atualmente mais de 10 milhões de estudantes, fica atrás apenas dos Estados Unidos e da China em termos de alunado. Possui também um sistema de ensino superior bastante diversificado institucionalmente, contando com 323 universidades e mais de 13 mil instituições não universitárias. Essas instituições apresentam distintos perfis e vocações acadêmicas. Apesar do rápido crescimento do ensino superior, apenas $9 \%$ da população entre 18 e 24 anos se encontra absorvida pelo sistema.
Uma das características salientes do sistema de ensino superior indiano repousa na separação entre instituições de pesquisa - que estão concentradas nos Institutos de Pesquisa - e estabelecimentos voltados para atividades de ensino que, como tendência, têm sido realizadas pelas universidades. Apesar de possuir uma imensa população ávida por oportunidades educacionais e de manter historicamente uma tradição de liberdade de expressão acadêmica, seu sistema de ensino superior situa-se num patamar aquém do existente na China e em outros países emergentes. Com exceção de alguns institutos de pesquisa, destacadamente o Instituto Indiano de Tecnologia (IITs), o Instituto Indiano de Administração (IIMs), o Instituto Indiano de Ciências Médicas (IIMs) e o Tata Instituto de Pesquisa Fundamental (TIFR), o sistema de ensino superior apresenta uma estrutura inadequada para absorver a demanda de acesso e possui também um padrão acadêmico considerado de qualidade insatisfatória (Altbach; Jayaram, 2009; Jayaram, 2007).

No período subsequente à sua independência política, o então primeiro-ministro Jawaharlal Nehru criou os Institutos de Pesquisa, estabelecendo parcerias com instituições prestigiosas do ocidente. Embora os IITs possuíssem a intenção de fornecer pesquisadores bem treinados academicamente, esse objetivo não foi plenamente atingido, uma vez que não conseguiram atrair estudantes promissores do ponto de vista científico e profissional. Boa parte dos estudantes mais talentosos na área de ciências tem escolhido as universidades estrangeiras para continuar sua formação acadêmica, principalmente as americanas, e dificilmente tem retornado ao país. Por outro lado, empresas multinacionais oferecem salários competitivos para recém-egressos dos IITs - que, na maioria das vezes, são recrutados no próprio campus -, minimizando as chances de eles continuarem seus estudos em programas de pós-graduação nesses institutos e (ou) ingressarem na carreira acadêmica que, em geral, oferece baixos salários. A pouca atração que 
exerce a carreira acadêmica na Índia produziu uma conjuntura na qual, numa oferta de quatro vagas para a profissão de docente no ensino superior, pelo menos uma não é preenchida.

A ausência de uma infraestrutura acadêmica capaz de produzir um corpo docente treinado em cursos de pós-graduação faz com que mais da metade dos professores que atuam no ensino superior na Índia não possua o título de mestre, tampouco o de doutor. Além de apresentar uma deficiente qualificação acadêmica, os docentes possuem pesada carga horária e ministram seus cursos para classes superlotadas de estudantes. Por outro lado, os laboratórios se encontram em estado de dilapidação física e material. Uma rígida política de ação afirmativa, voltada para o recrutamento de professores e estudantes provenientes de castas que ocupam uma posição dominada no sistema de estratificação social hindu - às quais são reservadas mais de $20 \%$ das vagas -, tem levado a universidade a absorver tanto alunos como docentes com deficiente preparo intelectual (Altbach; Jayaram, 2009).

Diante dessa situação insatisfatória, o governo central, apoiado nos estudos realizados pela Comissão Nacional de Conhecimento, lançou, em 2008, um ambicioso plano de reformas para enfrentar os aspectos disfuncioเป็ nais do ensino superior na Índia. Tal como está do em vários países, o governo central prevê a criação de 30 world class universities e a construção de oito novos IITS, sete IIMS e 12 novas universidades centrais. Para cobrir os custos, o governo destinou a aplicação de 2,2 bilhões de dólares, que também serão in× vestidos para elevar os salários dos docentes ¿ universitários em 70\% (Neelakantan, 2009). no superior indiano. Nesse sentido, apontam a existência de uma esclerosada burocracia que governa a vida acadêmica, de plágios e fraudes nos exames escolares e de favoritismo no recrutamento de docentes, além da ausência de uma institucionalização da pesquisa na estrutura universitária e de incentivos para os docentes desenvolveram práticas inovadoras no ensino. Esse conjunto de fenômenos contribui para a existência de uma cultura de mediocridade acadêmica, pouco propícia para o estabelecimento de world class university (Altbach; Jayaram, 2009).

Enquanto China e Índia têm concentrado a atenção nos seus esforços para se posicionar de maneira competitiva nos rankings internacionais, não se pode deixar de assinalar as tentativas que a Arábia Saudita vem implementando. Desde o pós-guerra, a economia local, baseada na exploração do petróleo, vem experimentando um desenvolvimento econômico contínuo. O governo central tem a expectativa de que suas universidades possam gerar novos conhecimentos como um fator inesgotável de geração de riquezas, além dos rendimentos advindos da atividade petrolífera. A Arábia Saudita também entrou na corrida para construir sua própria universidade de padrão mundial. Em 2009, foi inaugurada a King Abdullah University of Science and Techonology (Kaust), que assumiu a missão de integrar ensino e pesquisa e de contribuir para a diversificação econômica e tecnológica da Arábia Saudita. Com o propósito de se tornar uma instituição de excelência acadêmica, tem procurado incorporar, em seu quadro docente, professores e pesquisadores de várias nacionalidades. Objetivando desenvolver suas atividades num patamar de excelência acadêmica, estabeleceu parcerias com várias numerosas instituições de outros países, tais como o departamento de engenharia mecânica da Universidade da Berkeley, o Instituto de Engenharia da Universidade do Texas, o departamento de ciência da computação da Universidade de Stanford, o departamento de ciências biológi- 
cas da Universidade de Cambridge etc.

$\mathrm{Na}$ inauguração da King Abdullah University of Science and Technology (Kaust), a instituição recebeu uma doação de 10 bilhões de dólares por parte do Rei Abdullah e estimase que, em curto prazo, o aporte financeiro do governo central alcance a cifra de 25 bilhões de dólares, o que a tornaria a segunda universidade do mundo em termos de recursos financeiros, atrás apenas de Harvard. Com o propósito de criar uma estrutura administrativa ágil, a nova universidade não estará sob o controle burocrático do Ministério da Educação. Seu comando ficará a cargo da companhia nacional de petróleo, conhecida mundialmente pela sua cultura e eficiência administrativa. Simbolizando sua ambição de se tornar uma universidade competitiva no sistema transnacional de ensino superior, seu primeiro presidente Choon Fong Shih - obteve sua formação acadêmica em Harvard e, posteriormente, atuou com grande dinamismo na presidência da Universidade de Singapura. Simultaneamente, a Kaust formou um conselho consultivo integrado por experientes acadêmicos internacionais, tais como Frank Rhodes, presidente emérito da Universidade de Cornell, Frank Press, presidente emérito da Academia Nacional de Ciências dos Estados Unidos, Richard Sykes, reitor do Imperial College London etc. (Krieger, 2007).

Apesar de todo o esforço do governo central de impulsionar o ensino superior na Arábia Saudita, o recrutamento de professores estrangeiros se depara com obstáculos provenientes de um regime político autoritário, que aplica rígidas regras de conduta mulçumanas, tais como segregação de gêneros, estrita proibição de consumo de álcool, interdição às mulheres de dirigirem automóveis e a imposição de utilizar trajes que as cubram quase completamente em espaços públicos. Essas iniciativas de modernização do sistema de ensino superior colidem com práticas culturais tradicionais, como limitar o acesso de mulheres ao mercado de trabalho. A transmissão de um conservantismo cultural aos estudantes do sexo masculino tende a impedir a adaptação de seus estudantes num mundo globalizado, que experimenta profundas transformações culturais e de mentalidades (Baki, 2004).

Enquanto existe uma corrida desenfreada na Ásia e no Oriente Médio, com o propósito de tornar o ensino superior de alguns países da região competitivo no cenário mundial, no continente europeu se constata também uma série de iniciativas em vários países objetivando aumentar a competitividade de suas universidades no contexto da globalização, norteadas pela Comissão Europeia. Uma compreensão mais exaustiva da recepção do modelo de world class university no contexto europeu implicaria contrapor essa concepção de universidade com a existência de uma cultura acadêmica secular que, em larga medida, estruturou a própria trajetória do ensino superior ao longo do tempo (Deem; Mock, 2008; Fallon, 1980). Certamente, a análise dessa questão é pertinente; no entanto, por questão de espaço, não será realizada neste trabalho. A título de evidenciar o impacto da corrida pela construção de universidade de padrão mundial no continente europeu, serão abordadas, com brevidade, determinadas mudanças que estão ocorrendo no ensino superior alemão.

Na avaliação de Daniell Fallon, realizada em seu clássico livro The German University: a heroic ideal in conflict with the modern world, a súbita passagem de uma instituição de ensino voltada para a formação de uma elite cultural para uma instituição de massa nos anos 1960 acarretou uma situação desfavorável para a universidade alemã. Em sua apreciação, a partir do final da década de 1960, a universidade alemã repentinamente absorveu um número expressivo de estudantes com um quadro docente insuficiente. Segundo sua análise, além do processo de massificação, a universidade alemã foi enfraquecida pela concepção de que ela deveria possuir uma estrutura homogênea, ou seja, deveria oferecer cursos semelhantes em seu território, possuir uma mesma carreira docente, independentemente de sua localiza- 
ção geográfica. Em função desse cenário, por volta de 1980, as universidades alemãs deixaram de ocupar uma posição de referência no plano internacional e ocorreu um declínio no número de estudantes estrangeiros no seu interior (Fallon, 2008).

Nas últimas décadas, o ensino superior na Alemanha vem passando por significativas mudanças, entre as quais vale mencionar: (i) crescente autonomia de gestão das universidades diante da regulação estatal; (ii) publicização do cumprimento de metas institucionais propostas; (iii) ênfase na pesquisa científica e sua articulação com inovação tecnológica; (iv) tratamento diferenciado por parte do Estado para as universidades em função dos níveis de qualidade acadêmica; (v) avaliação de desempenho acadêmico como critério na distribuição de fundos governamentais; (v) gradativa diferenciação salarial do corpo docente em função de resultados das atividades de ensino e pesquisa; (vi) expressivo aumento da absorção de estudantes estrangeiros como estratégia de internacionalização;(vi) utilização recorrente da língua inglesa nas atividades acadêmicas (Kehm, 2013).

Em 2005, foi lançado o Programa Exzellenzianitiative (Excelência Iniciativa), com o propósito de apoiar medidas inovadoras no 올 ensino superior, contando com 1,9 bilhões de euros provenientes de recursos do governo federal e de governos estaduais. Esse programa incentiva a disputa pelos fundos financeiros por parte das instituições que oferecem programas de doutoramento, por grupos de pesจ quisa interdisciplinar e por projetos institucio+ nais que se propõem a realizar transformações \& relevantes no interior da universidade, com o

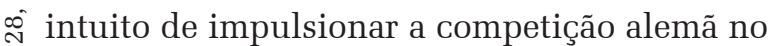

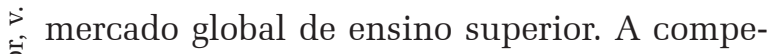
tição pelos recursos disponibilizados pelo Programa é extremamente disputada, e os projetos apresentados são julgados por renomados cientistas estrangeiros. Esse Programa possui o claro objetivo de criar um número restrito de universidades alemãs como world class univer- sity, e ocupar posições de destaque nos rankings internacionais, especialmente o criado pela Universidade de Shangai (Kehm, 2009).

Diante dessa situação, em 2004, o governo federal alterou a rota de funcionamento do ensino superior: o igualitarismo financeiro, que prevalecia até então na relação do governo com as instituições, foi substituído por uma política que passou a privilegiar e a incrementar as melhores instituições que realizam pesquisa e que possuem formação doutoral de elevado padrão. Em 2006, foi lançado um programa com o propósito de apoiar iniciativas de excelência no ensino superior, contando com 19 bilhões de euros, sendo que o governo federal responde por $75 \%$ dos recursos e os estados com a parte restante. Esse programa prevê a disputa pelos fundos financeiros por parte das instituições que oferecem programas de doutoramento, por grupos de pesquisa interdisciplinar e por projetos que se proponham a realizar transformações relevantes no interior da universidade, com o intuito de impulsionar a competição alemã no mercado global de ensino superior. O processo de competição pelos recursos disponibilizados por esse programa é extremamente disputado e possui explicitamente o objetivo de impelir as universidades alemãs a atingirem um padrão global. Essas iniciativas começaram a produzir resultados encorajadores. O número de estudantes internacionais que realizam estudos superiores na Alemanha tem crescido nos últimos anos, ficando atrás apenas de Estados Unidos e Inglaterra (Labi, 2008; 2006).

\section{CONSIDERAÇÕES FINAIS}

Por um longo período do tempo, os sistemas nacionais de ensino superior estruturaram-se e funcionaram, fundamentalmente, no âmbito circunscrito das fronteiras dos diversos países. Certamente, essa circunstância não inviabilizou a existência de eventuais intercâmbios acadêmicos entre diversos países 
em diferentes épocas. No entanto, a partir de meados da década de 1960, paulatinamente, surgiu uma constelação de novos fenômenos direta e indiretamente relacionados com o ensino superior, o que modificou sensivelmente o seu modus operandi de tal maneira, que o impulsionou a estender sua presença e sua ação para além das fronteiras nacionais. Este artigo abordou, de forma abreviada, alguns desses fenômenos, tais como o incremento da mobilidade acadêmica em nível internacional, o surgimento dos rankings globais, a frenética corrida mundo a fora para criar world class university, etc. Tal como ocorre com as esferas econômica, política e cultural no processo de globalização, o ensino superior não se confina mais nos limites das sociedades nacionais. Em função dessa dinâmica, o ensino superior contemporâneo possui duas dimensões - sistemas nacionais e sistemas transnacionais - que mantêm diversas modalidades de relações reciprocas.

Ao lado desses fenômenos, o presente artigo ressaltou o impacto direto e indireto do processo de globalização na dinâmica do ensino superior contemporâneo. Nesse sentido, o processo de globalização, cujos contornos estão adquirindo maior clareza nos diais atuais, acarretou profundas transformações na natureza da universidade. O modelo humboldtiano, que orientou por um longo período histórico a estruturação da autonomia intelectual da vida acadêmica, gradativamente passou a ser contraposto diante de novos arranjos institucionais. Nesse sentido, o artigo ressaltou que, a partir das últimas décadas do século passado, vem se delineando uma nova concepção de universidade, a qual atribui a essa instituição um protagonismo estratégico no crescimento das economias nacionais e um papel no incremento da competitividade dos países no contexto da economia global.

A configuração do ensino superior nas sociedades contemporâneas vem adquirindo, cada vez mais, uma dimensão relacional, ou seja, as universidades e seus respectivos países estão constantemente se comparando uns com os outros a partir de indicadores que expressem o prestígio nacional e (ou) internacional de cada um deles. Tudo leva a crer que a emergência dos rankings globais transformou o ensino superior num acirrado espaço de competição manifesta e (ou) latente, em busca de prestígio acadêmico e social, e a reconversão desse reconhecimento em captação de recursos financeiros para as instituições que o integram. No contexto atual, certamente, cada instituição de ensino superior possui a liberdade de estabelecer seus objetivos e missões acadêmicas. No entanto, tudo leva a crer que nenhuma delas comanda inteiramente seus próprios destinos, uma vez que elas constituem parte de um vasto e complexo sistema nacional e global marcado por uma crescente luta concorrencial.

Embora o Brasil possua universidades de alta qualidade acadêmica, elas ocupam posições bastante modestas nas avaliações internacionais. Caso o país tenha a ambição de ocupar posição de destaque no ensino superior internacional, torna-se necessário desenvolver políticas específicas para determinadas instituições que tenham o potencial acadêmico para se constituírem como universidades de padrão de excelência mundial, nas quais a pesquisa ocupe uma posição preponderante. Para tanto, é fundamental desatar os nós asfixiantes do centralismo burocrático estatal, implementar uma efetiva autonomia institucional, incrementar o recrutamento de professores e estudantes estrangeiros e analisar criticamente a pertinência de um paradigma isonômico que se encontra presente em várias dimensões das universidades federais.

$\mathrm{O}$ conhecimento das significativas mudanças que estão ocorrendo no ensino superior no plano internacional - impulsionadas pelo processo de globalização econômica, cultural e científica - deveria contribuir para desnaturalizar o funcionamento do ensino público no país, destacadamente o das universidades federais, e (re)pensar criticamente sua estrutura. Pode fornecer também um frutífero subsídio de informações capazes de alargar os horizontes 
intelectuais, visando a analisar a inserção do ensino superior brasileiro diante dos desafios postos pelo processo de globalização.

Recebido para publicação em 15 de janeiro de 2015 Aceito em 15 de março de 2015

\section{REFERÊNCIAS}

ALTBACH, P; JAYARAN, N. India's effort to join 21 century higher education. International Higher Education, n. 54 Winter, p. 17-19, 2009. Disponível em: <https:// htmldbprod.bc.edu/prd/f?p= 22 90:4:0::NO:RP, 4:P0 CONTENT_ID:101396>.

KNIGHT. The internationalization of higher education: motivations and realities. The NEA almanac of higher education. p. 27-36, 2006.

The cost and benefits of world class university. International higher education. The Boston College Center for International Higher Education. n. 33, p. 21-23. 2003. Disponível em: <https://www.bc.edu/content/dam/files/ research_sites/cihe/pdf/IHEpdfs/ihe33.pdf $>$.

Higher educations crosses the borders. Change. v. 36, n. 2, p. 18-25, 2004.

Rankings Season is here. International higher education. n. 62, p. 2-5, Boston, 2001.

ANTUNES, F. Globalização e europeização das Políticas educativas. Sociologia: problemas e práticas, n. 47, p. 125143, Lisboa, 2005.

BAKI, R. Gender segregated education in Saudi Arabi: its impacts on social norms and the Saudi labor market. Education policy analysis archives, v. 12, n. 28, p. 1-12, 2004.

BANKS, M. et. al. Global student mobility: an Australia perspective five years on. IDP. Education Pty. Sidney, 2007.

BAUMAN, Z. On education. Londres: Polity Press, 2012.

Universities: old, new, and different. In: The postmodern University?: contested visions of higher ㄴ) education in society. Anthony Smith e Frank Webster 今 (Orgs). Open University Press, 1997.

$\dot{\circ}$ BHANDARI, R.; BLUMENTHAL, P. International students $\$$ and global Mobility. In: Higher education: national trends .) and new directions. Palgrave, Nova York, 2011.

BRADDOCK, R.; TAYLOR, P. International University $\infty$ Ranking Systems and the Idea of University Excellence. \% Journal of Higher Education Policy and Management. v. 29, ริ n. 3, p. 245-260, 2007.

¿ BROOKS, R.; WATERS, J. Student mobilities, migration $\rightarrow$ and the internationalization of higher education. Nova $\stackrel{\star}{\wedge}$ Iorque: Palgrave, 2013.

वं

CASTELLS, M. The University system: engine of $\stackrel{\sim}{\infty}$ development in the new world economy. In: SALMI, J. $>$ Revitalizing Higher Education, Oxford: Pergamon, 1994.

of CLARK, B. On higher education: select writings (1956-2006). B. Baltimore: The Johns Hopkins University Press, 2008.

Higher education American Style: a structural model for the world. Educational Record, 1990. CURRIE, J. Globalizing practices and university responses. European and Anglo-American Differences. Boston: Praeger Publishers, 2003.

DEEM, R. Globalisation, new managerialism, Academic
Capitalism and Entrepreneurialism in Universities: is the local dimension still important? Comparative Education, v. 37, n. 1, 2001.

; MOK, K. Transforming higher education in whose image? Exploring the concept of the "world-class" university in Europe and Asia. Higher Education Policy, n. 21, p. 83-97, 2008.

DELANTY, G. The cosmopolitan imagination: the renewal of critical theory. Cambridge: Cambridge University Press, 2009.

The University in the Knowledge Society. London: Open Univesity, 2002.

DOUGLAS, J.; KING, J. (Orgs) Globalization's muse: universities and higher education in a changing world. Berleley: Berkeley Public Policy Press, 2009.

ENDERS, J. Higher education in a globalising world. Boston: Kluwer Academic Publishers, 2002.

FALLON, D. Germany's excellence iniciative. International Higher Education, n. 52, p. 16-18, Boston, 2008.

The german university: a heroic ideal in conflict with the modern world. Colorado Associated University Press, 1980.

FERREIRA, J. B. Globalização e ensino superior: a discussão de Bolonha. Revista Perspectiva, v. 24, n. 1, p. 229-242, Florianópolis, 2006.

GEIGER, G. American research universities since world war II: research \& relevant Knowledge. Londres: Transaction Publishers, 2004.

GIBBS, P. The comodization and standardizationof higher education in globalization and internalization in higher education theoretical, strategic and management perspectives. Maringe. F.; Foskett. N. (Orgs). London: Continuum International Publishers, 2010.

GIBBONS, M. Globalization, innovation and socially robust knowledge. In: The university in the global age, Roger King(org), Londres: Palgrave, 2004.

Higher education relevant the 21st century. Washington: The World Bank, 1998.

GREEN, M.; KOCH, K. The competiton for International postsecondery education students. International Higher Education, v. 10, p. 13-14, 2010.

GUADILLA, C. Tensiones y transiciones: educación superior latinoamericana en los albores del tercer milenio. Caracas: Editorial Neuva Sociedad, 2004.

GUO, W. The quest for world class in China: critical refletions. Policy Futures in Education, v. 6, n. 5, p. 545-557, 2008.

GÜRÜZ, K. Higher education and international student mobility in the global knowledge economy. Albany: State University of New York Press, 2008.

HARVEY, P.; THORNS, D. Place, Identity $\&$ Evereday in a globalizing world. Nova York: Palgrave, 2012.

HAZELKORN, E. Rankings and the reshaping of higher education. Londres: Palgrave, 2011.

. Learning to live with league tables: the experiences of institutional leaders. Higher Education Policy, v. 21, p. 193-216, 2008.

HELD, D.; McGREW, A. (Orgs). Globalization theory: approaches and controversies. Cambridge: Polity, 2012.

HILLS, E. The calling of education: the academic ethic and another essays on higher education. Chicago: The University of Chicago Press, 1997.

HO.K.H. Peering through the dust of construction: Singapore's effort to build WCUs. In: SHIN, Jung e KEHM, Barbara (Org). Institutionalization of world class university in global competition. Londres: Springer, 2013. 
HVISTENDAHL, M. China moves up to fifth as importer of students. Chronicle of higher education, 19 set. 2008.

JAYARAN, N. Beyond Retailing Knowledge: prospects of research-oriented universities in India. In: ALTBAH, P.; BÁLAN, J. (Orgs). Transforming research universities in Asia and Latin America, Baltimore: The Johns Hopkins University Press. 2007.

KERR, C. The uses of the university. Cambridge: Harvard University Press, 2001.

KAUFMANN, V. Re-Thinking Mobility: contemporary sociology. Ashgate: Aldershot, 2003.

KEER, Clark. The uses of the university. Harvard University Press.Cambridge.2001.

KEHM, B. To be or not to be? The impact of the excellence initiative on the german system of higher education. In: SHIN, Jung; KEHM, Barbara (Org). Institutionalization of world class university in global competition. Londres: Springer, 2013.

The german "excellence initiative" and its role in restructuring the national higher education landscape. In: PALFREYMAN, D.; TAPPER, T. (Orgs). Structuring mass higher education: the role of elite institutions. Londres: Routledge, 2009.

KING, R. The contemporary university. In: The university in the global age. Londres: Palgrave. 2004.

KNIGHT, J. Higher education in turnoil: the changing world of internationalization. Rotteradam: Sense Publishers, 2008.

Gats, trade and higher education: where are we? Londres: The Observatory on Borderless Higher Education, 2003.

KRIEGER, Z. Saudi Arabia puts its billions behind western-style higher education. Chronicle of higher education, 14 set. 2007.

KWIEK.M. The University and the state: a study into global transformations. Nova York: Peter Lang Publisher, 2006.

LABI, A. Germany's share of foreign student market begins to stagnate. Chronicle of Higher Education. $1^{\circ}$ mai. 2008.

. Germany awards elite status, and $\$ 26$ - Million to 3 University. Chronicle of Higher Education. 27 out. 2006.

LEMERT, C.; ELLIOT, A. Globalization: a reader. Nova York: Routledge, 2010.

LING, R. New Tech, New Ties: how mobile communications is reshaping social cohesion. Cambridge: MIT Press, 2008.

LIU, N. C.; WANG, Q.; CHENG, Y. Paths to a World Class University: lessons from practices and experiences. Boston: Sense Publishers, 2011.

The story of Academic Ranking of World Universities. International Higher Education. Boston, n. 54, p. 2-3, 2009.

MANICAS, P. Globalization and higher education. Honolulu: University of Hawaii Press, 2004.

MARGISON, S. et. al. Handbook on globalization and higher education. Massachussets: Edward Elger. 2011.

MARINGE, F; FOSKETT, N. (Orgs) Globalization and internationalization in higher education: theoretical, strategic and management perspectives. London: Continuum International Publishers, 2010.

MOHRMAN, K.; BAKER, D. The research university in transition: the emerging global model. Higher education policy, p. 5-27, n. 21, 2008.

NEELAKANTAN, S. India plans big budget increase to finance higher education expansion. Chronicle of Higher Education, 20 fev. 2009.

NEVES.C.B. Reforma e desafios da educação superior: o processo de Bolonha dez anos depois. Sociologia e Política. Revista do Programa de Pós-graduação em Sociologia e Antropologia da Ufrj. v. 1. p. 181-208.2011.

O'BYRNE, D.; HENSBY, A. Theeorizing global studies.
Nova York: Palgrave, 2011.

OGER, C. Le façonnages des élites de la Republique. Culture genérale et haute fonction publique. Paris: Science Po., 2008.

OCDE. Internationalization and trade in higher education: opportunities and challenges, Paris, 2004.

PERKINS, H.; THORNS, D. Place, Identity and everyday life in a globalizing word. Nova York: Palgrave, 2012.

READINGS, B. The university in ruins. Cambridge: Harvard University Press, 1996.

ROBERTSON, R. Globalization: social theory and global culture. Londres: Sage Publication, 2000.

ROBERTSON, S. L. The emerging political economy of higher education, Studies in Higher Education, v. 23, n. 2, p. 221-228, 1998.

ROSTAND, M. English as "lingua franca" and the internationalization of academe. International higher education, n. 63, p. 11-13, 2011.

SALMI, J. The challenge of Establishing World-Class universities. Washington: The world bank. 2009.

SASSEN, S. A Sociology of globalization. New York: W.W. Norton \& Company, 2007.

. The global city. Princeton: Princeton University Press, 1991.

SAUDER, M.; ESPELAND, W. The discipline of rankings: tight coupling and organizational change. American Sociological Review, v. 74, n. 1, p. 63-82, 2009.

SCOTT, C. The Mision of the University. Medieval to Posmodern Transformations. Journal of Higher Education, Vol 77, n. 1, p. 2-39, 2006.

SCOTT, P. (Org). The globalization of higher education. Philadelphia: Open University Press. 1998.

THELIN, J. A History of american higher education. Baltimor: The Johns Hopkins University Press, 2004.

TROW, M. Twentieth-century higher education: elite to mass to universal. Baltimore: The Johns Hopkins Press, 2011.

TURNER, B.; ELLIOT. A. On society polity press. Cambridge, 2012.

- KHONDKER. Globalization: east and west. Londres: Sage. 2010

URRY, J.; ELLIOTT, A. Mobile lives. Oxford: Routledge, 2010. VERBIK, L.; LASANOWSKI, V. International student mobility: patterns and trends. Londres: The Observatory of Borderless Higher Education. 2007.

WANG, X. Expantion and differentiation. Chinese Higher Education. International Higher Education, n. 60, p. 7-8, 2010.

WENDE, M. Global institutions: the Organization for Economic Co-operation and Development. In: Handbook on globalization and higher education (Org) Simon Marginson e col. Edward Elger, Massachussets, 2001.

. European Responses to global competitiveness in higher education. Center for Studies in Higher education. University of California, Berkeley, 2009.

WILDAVSKY, B. The great brain race: how global universities are reshaping the world. New Jersey: Princeton University Press, 2010.

WIT, H. Recent trendes and issues in international student mobility. International Higher Education, n. 59, p. 13-14, 2010.

WOODFIELD, S. Key trends and emerging issues in international student mobility. Felix Maringe e Nick Foskett (orgs) Globalization and internationalization in higher education: theoretical, strategic and management perspectives. London: Continuum International Publishers, 2010. 


\section{NOTES ON THE FORMATION OF A HIGHER EDUCATION SYSTEM TRANSNATIONAL}

\author{
Carlos Benedito Martins
}

This article having as analytical reference the reciprocal relationship between globalization and higher education, aims to approach some changes that are taking place in higher education in contemporary societies. Supported by a pertinent literature to the subject, the article pointed out that in the context of globalization, higher education is not confined more within the national societies, but overflows beyond its borders. The article indicates the emergence of certain events that occurred in recent decades leading higher education to work in a transnational space. The information provided by article tend to indicate that in contemporary societies higher education is acquiring an increasingly relational dimension, so that universities and their respective countries are constantly comparing yourself and competing with each other in search of the academic prestige in the international context of higher education.

KEY WORDS: Deterritorialization of higher education. International academic mobility. International rankings. World class university

\section{NOTES SUR LA FORMATION D'UN SYSTÈME D'ENSEIGNEMENT SUPÉRIEUR TRANSNATIONAL}

\author{
Carlos Benedito Martins
}

Cet article, ayant comme référence analytique la relation réciproque entre la mondialisation et l'enseignement supérieur, vise à analyser les changements qui opèrent au enseignement supérieur dans les sociétés contemporaines. Soutenu par une bibliographie pertinente au sujet, l'article fait remarquer que dans le contexte de la mondialisation, l'enseignement supérieur ne se limite pas plus aux sociétés nationales, mais déborde au-delà de ses frontières. L'article indique l'émergence de certains événements qui se sont produits au cours des dernières décennies qui ont conduit l'enseignement supérieur à opérer dans l'espace transnational. Les informations fournies par l'article tendent à indiquer que, dans les sociétés contemporaines, l'enseignement supérieur acquiert une dimension plus relationnelle, de sorte que les universités et leurs pays respectifs sont constamment en comparaison et en concurrence les uns avec les autres, tous à la recherche du prestige académique dans le contexte international de l'enseignement supérieur.

Mотs CLÉs: Déterritorialisation de l'enseignement supérieur. La mobilité académique internationale. Les classements internationaux. L'université de classe mondiale

Carlos Benedito Martins - Doutor em Sociologia. Professor Titular da Universidade de Brasília (UnB), Instituto de Ciências Humanas, Departamento de Sociologia. Realizou pós-doutoramento na Universidade de Columbia. Coordenador da linha de pesquisa Educação Ciência e Tecnologia do Programa de Mestrado e Doutorado em Sociologia. Atualmente é um dos Coordenadores do GT Configurações do Ensino Superior Contemporâneo da ANPOCS e do GT Educação Superior na Sociedade Contemporânea da Sociedade Brasileira de Sociologia (SBS). É vice-presidente da Sociedade Brasileira de Sociologia (20132015). Membro do Comitê de Assessoramento Institucional da Associação Nacional de Pós-Graduação e Pesquisa em Ciências Sociais ANPOCS (2014-2016). Áreas de atuação: Teoria Social, sociologia da educação e do ensino superior. Publicações recentes: Passado e presente da Sociologia Norte-americana. Revista Brasileira de Ciências Sociais (Impresso), v. 30, p. 163-169, 2015; Em defesa do conceito de sociedade. Revista Brasileira de Ciências Sociais (Impresso), v. 28, p. 229-246, 2013; Reconfiguring higher education in Brazil: the participation of private institutions. Análise Social, v. XLVIII, p. 622-658, 2013. 